\title{
A Needs Analysis for Technology Integration Plan: Challenges and Needs of Teachers
}

\author{
Sinem Vatanartiran \& Sirin Karadeniz \\ Bahcesehir University, Turkey
}

\begin{abstract}
Lack of technology leadership and technology integration plans are important obstacles for using technology effectively in schools. We carried out a large-scale study to be able to design a technology integration plan for one of the pilot provinces that Fatih Project was initiated. The purpose of this research is to examine the perceived challenges and needs of K12 teachers when integrating technology into their classes, which would be used as the needs analysis data of the technology integration plan. A mixed design was used and 844 teachers participated in the study. An online survey was used to gather both the quantitative and qualitative data. The findings showed that there are three major issues for teachers to integrate technology into their instruction: Executive, infrastructural, and instructional. Executive issues are mostly related to managerial and financial challenges, Infrastructural issues include technological and physical challenges, and instructional issues consist of challenges related with instructional materials, students' readiness, and teacher competencies.
\end{abstract}

Keywords: FATIH project; Technology integration plan; Needs analysis; Teacher training; Change management.

\section{Introduction}

The world has become such a place that it is impossible to move a step forward without technology. It is even possible to say that in the future (it may be such a close future), the world will be run by technology companies, not countries and that every technology company will have its own citizens, culture, identity, and economy.

This technological progress has inevitable educational implications. According to the figures cited by Mosenson and Johnson (2008), more than 21 million individuals in the 12 to 17 age group (87\%) use Internet, while 16 million (78\%) use it at school in the USA. USA has invested over $\$ 66$ billion in school technology (Quality Education Data, 2004 cited by Mosenson and Johnson, 2008). Despite the current budget challenges, $65 \%$ of school districts in the United States plan to increase technology investments in the classroom over the next two years (CDW Government, 2012 cited by Grundmeyer, 2013). Curriculum content also ensures that students have computer experience in many subjects and in many formats, ranging from games that teach multiplication tables to Internet-based research projects (Murdoch, 2004 cited by Grundmeyer, 2013). Use of technology in educational settings effectively requires change in pedagogical beliefs, attitudes, and practices. Traditional school cultures are challenged with the invasion of technology into school settings, sometimes mandatorily from top to bottom. Ultimately, the necessary cultural change to utilize technology meaningfully and effectively into learning environments begins with school leadership and teachers as agents of change as 
in many other educational change efforts/initiatives. Research has shown that "a school's ICT vision is integral to effective, appropriate, and sustainable ICT integration" (Afshari, Bakar, Luan, Samah, \& Fooi, 2009).

The use of ICT in education brought new pedagogical models as well. TPACK is a form of teacher expertise derived from the multiple knowledge bases of Technological Knowledge (TK), Pedagogical Knowledge (PK), and Content Knowledge (CK) (Mishra \& Koehler, 2006). Mishra and Koehler emphasized that teachers' technology integration expertise emerged from the connections between these sources of knowledge. Therefore, PCK, TPK, TCK, and TPACK are the important sources of knowledge to develop among the seven TPACK constructs (Koh \& Divaharan, 2013).

\section{Barriers for ICT Integration}

Nevertheless, there are certain barriers and challenges in the implementation of ICT to educational environments. Brickner (1995) categorized these barriers into two: extrinsic and intrinsic. Extrinsic barriers are related to infrastructure while intrinsic barriers are more human centered, related with beliefs and attitudes. The literature pointed barriers for successful technology integration at schools in regards with teachers as knowledge, skills, and having training on technology and how to use it in the classroom (Akkoyunlu, 1995; Albirini, 2006; Cakir \& Yildirim, 2009). In addition, Lai, Pratt, and Trewern (2011) suggested that confidence level and pedagogical beliefs regarding the value of the use of technology are barriers that hinder technology use in classroom. Hew and Brush (2007) further identified the general barriers typically faced by K-12 schools as: resources, institution, subject culture, attitudes and beliefs, knowledge and skills, and assessment.

Literature suggests ways of overcoming these barriers as well. Successful implementation of ICT necessarily requires the involvement of stakeholders and issues of leadership (Allan, Yuen, and Wong, 2003, p. 161). The leadership required for the ICT implementation is mostly related with change management. According to Fullan (1992), there are three dimensions of change for the teacher using computers in the classroom: (a) the use of new hardware and software materials, (b) the adoption of new activities, behaviors or practices, and (c) changes in beliefs and understanding.

ICT is an innovation that can promote and foster various degrees of organizational change (Allan, Yuen, and Wong, 2003, p. 169). A survey on nearly 1,000 school principals and technology coordinators found that 80 percent of the schools surveyed under-utilize technology they have already purchased (Moeller \& Reitzes, 2011). Research on technology integration that has been conducted over the past 20 years sheds some light on why technology is not used more, highlighting the importance of organizational factors, teacher factors, and factors associated with the technology itself (Moeller \& Reitzes, 2011). According to Moeller and Reitzes, aspects of organizational support for technology integration are a school culture that promotes technology use; a coherent, shared pedagogical vision for technology use, and support from peers, administration, and the community; availability of technical support; technology policies (e.g., regarding cell phone use and access to internet resources); a culture of collaboration in which teachers work together to explore more effective uses of technology; and assessment systems that go beyond multiple-choice tests and that measure changes such as deeper understanding and improved problem solving that result from effective technology use. 
In their meta-ethnographic study of 19 research papers conducted in six different countries, Tondeur, Braak, Sang, Voogt, Fisser, and Ottenbreit-Leftwich (2012) identified seven key themes explicitly related to the preparation of pre-service teachers, five key themes about conditions necessary to implement such programs at institutional level, and the overarching model. The five key themes related with the implementation phase of technology into schools are technology planning and leadership, co-operation within and between institutions, staff development, access to resources, and systematic and systemic change efforts.

\section{Technology Planning Models}

Roblyer (2006) identifies shared vision, technical assistance, standards and curriculum support, trained personnel, and access as five essential conditions for technology integration. In their study of 18 schools and their adoption of ICT into schools, the researchers identified 3 models of change management and that the key distinctions between these three models are the established vision and values of the school, the perceived role and impact of ICT in education and the established culture and reform history of the school (Allan, Yuen, and Wong, 2003, p. 164). The first model is the Technological Adoption Model where the emphasis is on managing the adoption of technological infrastructure, organizational structure and teachers' technical skills. These schools did not have strong traditions or cultures, emphasis is on sharing of teacher-produced course materials as one key implementation strategy and the leadership strategy is top-down management to ensure all teachers reach minimum level of ICT competence and principals set clear targets and timetable for achieving specific ICT competencies. The second model is the Catalytic Integration Model, where interest was focused on ICT that supports and enhances the curriculum reform and the leadership strategy is visionary leadership with principal as the key change agent and top-down arrangement with teacher involvement is actively cultivated. The third model is the Cultural Innovation Model, where ICT is used as an empowering tool for both students and teachers and students are given opportunities to initiate new ideas with ICT themselves.

All of these different models require a project management and therefore a needs analysis is the first step of implementing such models. Needs assessment is the "systematic exploration of the divergence or discrepancy between the current situation or level of services ("what is") and the desired situation or level of services ("what should be")" (NOAA, 2009, p. 7). Through this careful analysis, the chance of duplicating the efforts of existing programs or becoming sidetracked is reduced. This also serves reaching underserved audiences. As noted by Kaufman and English (1979, p. 31), needs assessment "keeps us from running down more blind educational alleys, from using time, dollars and people in attempted solutions, which do not work."

\section{A Large Scale Project of Integrating Technology into Education: Fatih Project}

'Movement of Enhancing Opportunities and Improving Technology', known as FATIH (Turkish acronym), is among the most significant educational technology investments of Turkey and in the world. Its total cost is planned to be 8 billion TL (around 4 billion USD with today's currency). Turkey initiated FATIH Project with the aim of enabling equal opportunities in education and improving technology in the schools for the efficient usage of ICT tools in the learning-teaching processes in all 42.000 schools and 570,000 classes that are in the preschool 
education, the primary education, and the secondary education in the country through providing tablets and LCD Interactive Boards (MEB, 2012).

The pilot phase of the project was launched with the delivery of tablet PCs and LCD interactive boards to 52 schools across Turkey. High schools around the country were equipped with LCD interactive boards, and 8,500 tablet PCs were distributed in 52 schools in 17 provinces within a pilot program. In the expanded pilot phase, 49,000 tablet PCs were distributed to both students and teachers in the total of 81 provinces in Turkey.

There have been a number of studies about the effectiveness and challenges of this large scale project (Akcaoglu, Gumus, Bellibas, \& Boyer, 2014; Akgun, Yilmaz, Seferoglu, 2011; Akinci, Kurtoglu, \& Seferoglu, 2014; Ciftci, Taskaya, Alemdar, 2013; Genc \& Genc, 2013; Kayaduman, Sirakaya, and Seferoglu, 2011; Kurt, Kuzu, Dursun, Gullupinar, \& Gultekin, 2013; Pamuk, Çakir, Ergun, Yilmaz, \& Ayas, 2013; Uzoglu and Bozdogan, 2012). One of these studies examined 181 teachers and 918 students from 11 pilot schools in 4 provinces (Pamuk, et al., 2013) and concluded that interactive board was used for a variety of purposes at different levels whereas only a limited number of students and almost none of the teachers used the tablet PCs. They also concluded that there had been an increase in the interests and attitudes of teachers and students towards the use and getting benefit of technology since the beginning of the project. The main problems, however, are listed as not being able to use the classroom management software, insufficient e-content and digital books, technical obstacles, and the lack of inservice training and inadequate technical support. The authors suggest that teachers are trained and supported by using TPACK model.

\section{Purpose of the Study}

Lack of technology leadership and technology integration plans are also important obstacles of using technology at the schools as suggested by research (Gulbahar, 2007; Saban, 2007; Sugar \& Holloman, 2009). Many institutions are failing to effectively integrate technology into curriculum, and technology planning should be a way of solving existing problems faced during integration process (Gulbahar, 2007). We carried out a large-scale study to be able to design a technology integration plan for the province of Edirne, one of the pilot provinces that Fatih Project was initiated. The citywide implementation of the Fatih Project will be put into action with this technology integration plan based on this needs analysis. The purpose of the current research is limited to the needs analysis of the teachers focusing on the perceived challenges and needs of $\mathrm{K} 12$ teachers when integrating technology to their classes.

\section{Method}

In this study, a mixed research design was used. The triangulation design was preferred where the purpose is to "simultaneously collect both quantitative and qualitative data, merge data, and use the results to understand a research problem" (Creswell, 2008, p. 557). In this design, the researcher gathers quantitative and qualitative data, analyzes both datasets separately, compares the results from the analysis of both datasets, and makes an interpretation as to whether the results support or contradict each other (Creswell, 2008). In the present study, the perceptions of $\mathrm{K} 12$ teachers towards integration of ICT and the challenges they face were taken through a questionnaire that asks for both qualitative and quantitative data. 


\section{Participants}

There are a total of 4,020 K-12 teachers in the province of Edirne. An online survey was distributed to all of these teachers with the permission of the superintendent's office. 844 teachers submitted back this online survey. 745 answered the survey fully including the openended items. Among 745 teachers who answered the survey, 398 (53.4\%) were primary school teachers, 273 (36.6\%) were secondary school, and 74 (9.9\%) were high school teachers. These percentages represent the distribution of the total number of teachers to the school levels in this province.

Of the sample, 447 teachers $(60 \%)$ were female. The majority of the teachers were aged between 31 and 40 ( $n=273,36.6 \%), 225$ of them (30.2\%) were aged 41-50 years old, 185 of them $(24.8 \%)$ were 30 years old and under and only 62 of them were (8.4\%) 51 and above years old. The majority of these teachers had 16 and above years of teaching experience $(n=310,41.6 \%), 153$ of them (20.5\%) had 6 to 10 years of experience, 150 of them (20.1\%) had 1 to 5 years of experience and 132 of them (17.7\%) had 11 to 15 years of teaching experience. As for their educational attainment, a vast majority of them $(n=609,81.7 \%)$ had a bachelor's degree, 85 of them (11.4\%) had an associate degree, while 51 of them (6.8\%) had a graduate degree.

\section{Instruments}

Data were collected through an online survey designed by the researchers. The researchers designed the survey with the help of the literature review. The survey was designed in three sections. The first section includes demographic questions. The second section includes items on the access to technology at their schools, technology competency level as perceived by teachers, previous in-service teacher training on the use of technology, and the technologies they have in their classrooms. The third section of the survey consisted of three open-ended questions about challenges that teachers encountered while using technology, skills that teachers think they need to develop, and suggestions on designing an in-service training program.

\section{Validity and Reliability}

Maxwell $(2005$, p. 108) takes attention to two general threats to validity that are often raised in relation to qualitative studies: researcher bias and the effect of the researcher on the individuals studied. The researcher bias occurs when the researcher selects data that fit his/her existing theory or preconceptions and selects data that stand out to the researcher (Miles \& Huberman, 1994). To overcome this threat, the exact texts from the participants' survey were used directly by the researchers during the coding process. For the second validity threat, Maxwell (2005) suggests that eliminating the actual influence of the researcher is impossible and the goal in a qualitative study is not to eliminate this influence, but to understand it and to use it productively. The researchers presented the data objectively and used their personal interpretations only to interpret the findings and in the conclusion. As the data was collected as part of a survey and not through face-to-face interviews, the individuals studied were not faced with any personal influence of the researchers, as well. 
Reliability refers to the degree of consistency with which instances are assigned to the same category by different observers or by the same observer on different occasions (Silverman, 2000 , p. 188). To overcome this threat to reliability, intercoder reliability was implemented (Miles and Huberman, 1994). The researchers first coded the texts separately and then negotiated on the codes and their categories together. They shared their opinions on the categories each code belongs to and agreed on narrowing down the categories by eliminating any overlapping codes or redundancies. Only after a consortium on the codes and their categories, the final list of the themes, categories and codes were presented.

\section{Data Analysis}

To analyze the quantitative data, frequency analysis was used. The results were transformed into percentages to be presented in the study. The open-ended items to collect qualitative data were analyzed through content analysis. First, codes were formed and then these codes were grouped meaningfully to form consistent and distinct sub-categories after going back and forth among the data (Marshall \& Rossman, 1989). These categories were then integrated and refined until themes were solidified (Stratuss \& Corbin, 1998). Finally, these groupings were presented through tables. The researchers highlighted quotes and phrases from the openended answers that were significant to the study.

\section{Results and Discussion}

In this section, first the quantitative findings focusing on the working environments of the teachers involved in the study are presented. Then, the qualitative findings are presented with discussion.

\section{Working Environments}

In order to understand the working environments of the teachers better, quantitative data was collected related with their access to the technology they need, technologies they have in their classrooms, in-service training they had previously on the use of the technology, and the technology competency level as perceived by themselves.

The majority of the teachers ( $n=536,71.9 \%$ ) have access to technology they need at their schools. 513 teachers (68.9\%) have a projector, 380 teachers $(51.0 \%)$ have a PC, 192 teachers (25.8\%) have a laptop, 89 of them (11.9\%) have an interactive white board, 84 of them (11.3\%) have a tablet PC, $77(10.3 \%)$ have TV, and $55(7.4 \%)$ have a printer in their classrooms. Other technologies in the classrooms are scanner ( 3 teachers), sound system ( 2 teachers), VCD (2 teachers), DVD (1 teacher), Xerox machine (2 teachers). 12 teachers have no technology. These findings show that the majority of them have a projector and a PC in their classrooms.

Teachers were also asked how they would rate their competency level for use of technology and most of them $(n=208,56.1 \%)$ perceived themselves as competent on technology use. A vast majority of the teachers $(n=566,75.6 \%)$ attended an in-service training previously on the use of technology in classrooms. 


\section{Challenges When Using Technology}

The content analysis revealed three main themes: Executive issues, Infrastructural issues and Instructional issues. These themes and their subcategories are shown in Table 1.

Table 1. Themes and Categories for the Challenges of Use of Technology

\begin{tabular}{|c|c|c|}
\hline Main Themes & First Degree Categories & Second Degree Categories \\
\hline \multirow[t]{3}{*}{ Executive Issues } & Managerial & Lack of information flow \\
\hline & & Lack of managerial support \\
\hline & Financial & Lack of financial support \\
\hline \multirow{10}{*}{$\begin{array}{l}\text { Infrastructural } \\
\text { Issues }\end{array}$} & Technological & No/lack of technology in the classroom \\
\hline & & Problems with hardware \\
\hline & & Internet \\
\hline & & Technology outdated quickly \\
\hline & & Power outages/low voltage \\
\hline & & Delayed or no maintenance and repairment \\
\hline & Physical & Size of the classrooms (square footage) \\
\hline & & Teachers not having their own classrooms \\
\hline & & Multi-graded classrooms/time issue \\
\hline & & Over-crowded classrooms \\
\hline \multirow{10}{*}{$\begin{array}{l}\text { Instructional } \\
\text { Issues }\end{array}$} & Instructional Materials & Insufficient materials \\
\hline & & Lack of time \\
\hline & & Access to online materials \\
\hline & Students' Readiness & Technological literacy \\
\hline & & Internal motivation \\
\hline & & $\begin{array}{l}\text { Indifference of parents and their technological } \\
\text { incompetence }\end{array}$ \\
\hline & Teacher Competencies & Technological Pedagogical Knowledge \\
\hline & & Technological Knowledge \\
\hline & & Technological Content Knowledge \\
\hline & & Insufficient in-service training \\
\hline
\end{tabular}

Executive Issues

Under the theme of Executive issues, we have two major issues: Managerial and financial. Teachers complain that they face problems caused by lack of information flow especially from the administration about their expectations from teachers on their use of technology and about getting feedback. On top of this, teachers feel that they do not get necessary support from their principals when they share their technology related problems. According to teachers, this insufficient support is caused by limited school budget allocated for use of technology. They explain this by saying that "the management always uses finances as an excuse for not providing maintenance and repairment services". In addition, teachers do not have financial support for subscribing to educational sites and buying consumables and new technological equipment they need. 
A study of Akcaoglu et al. (2014) where 11 teachers were interviewed also concluded that one of the main implementation issues was lack of technical support and that teachers sought help from their more tech-savvy colleagues, and, in some cases, students. Lack of support from school principals was also defined as a major barrier to technology integration in other studies (Baylor \& Ritchie, 2002; Pelgrum, 2001). They can positively affect teachers' use of technology by providing feedback, resources, technical support, and up-to-date technology (ISTE, 2009).

\section{Infrastructural Issues}

Under Infrastructural issues, we have technological and physical issues as sub-categories. These infrastructural issues can be considered as the extrinsic barriers to ICT integration as expressed by Brickner (1995) and discussed in the Introduction part.

Some teachers mentioned that they had either no technology or lack of technology in their classrooms. Technologies they said they lack are sound system, printer or Xerox, smart board, projector, and desktop computer. As this study was carried out during the pilot phase of the large-scale project, not all of the classrooms were equipped with the PCs, projectors, and smart/interactive boards yet. Besides these, some teachers complained about not being able to use the board or blacking out the classroom when using the projector simultaneously. For those who had technology in their classrooms, hardware problems are the biggest challenge for integrating technology effectively. These problems are stated as cheap and poor quality equipment, incompatibility between smart board and some programs uploaded on their tablets/PCs, and out of date and slow hardware. Several teachers stated that the startup/shut down time of the PC is too long that it causes loss of class time and they simply do not want to use the PC for that reason. The maintenance problems slow down the use of technology in the classrooms, as well, together with technology dating out so quickly.

Such infrastructural problems exist in similar technology integration projects. In a study of high school 1:1 laptop initiative project (Grundmeyer, 2013), frustration was highlighted to upkeep of the laptops and that since most schools put newly leased or purchased laptops on a three to four year rotation, ongoing service and upkeep for the laptops were found to be important. As also noted by Tondeur et al. (2012), resources (such as hardware, software, learning material, documentation, etc.) are an important condition for technology integration.

Another infrastructural problem is that there is either no Internet or slow Internet connection in the classrooms. As part of the FATIH project, it is aimed to bring a fiber Internet connection to every school and every classroom. So, during the pilot phase, lack of Internet connection or the speed of it caused problems. In Grundmeyer's study (2013), similar internet connection problems were mentioned, too, as expressed by one of their study participants "the school has low bandwidth, thus slow Internet access speed, which inhibits students from using the technology". In addition to the internet connection problem, The Ministry of Education puts limitations and filtrations to certain sites on the tablets distributed to students and teachers. However, these limitations and filtrations are so strict that teachers have difficulty of accessing even several educational sites.

The third sub-category under this theme is the Physical issues. Under this category, we see the size of the classrooms both in terms of the square footage and number of students, teachers not having their own classrooms, and multi-graded classrooms as the major challenges for 
teachers. In Turkey, especially in public schools, students stay in the same classroom and subject area teachers visit them. Therefore, teachers do not have the chance to stay in one room, design it for their lessons, and display materials on their walls. Similarly, they do not have the technology they need ready to use in one classroom. This causes problems since teachers need to carry their own laptops to each classroom they go to and have to suffice with the technology they have in the different classrooms they use for instruction. Multi-graded classrooms are a problem in smaller districts and villages. In one school, there are 4 different grade levels in one classroom. Teachers in such schools say "as we are teaching multi-graded classrooms, we cannot use technology for 4 different grade levels at the same time. I have difficulty in finding appropriate activities and materials".

\section{Instructional Issues}

The first sub-category here is the instructional materials. Teachers complain about having not enough materials developed by the Ministry of Education. This complaint makes sense when taking into consideration the highly centralized structure where schools and teachers are expected to follow by heart the national curriculum prepared by the Ministry of Education and use textbooks that are prepared in accordance with this national curriculum. Teachers expect to have "animations related with the subject, online practices and tests to use for reinforcement, online experiments etc." According to some teachers, "the curriculum does not cover technology" meaning that the national curriculum is not prepared with directions on how to integrate technology. These comments show the dependence of teachers to the national curriculum and that they do not have the competence to empower their autonomy and develop their own materials.

This finding is confirmed with the results of the third sub-category Teacher Competences and will be discussed there more. The Thompson, Schmidt, and Davis study (2003) also focuses on the importance of systemic change process in integrating technology into curricula and suggests that a technology coordinator in the school meets with grade level teachers to plan integrated projects.

Another challenge in this category is lack of time to cover a variety of activities when using technology and that "time is not enough to cover them all". Karaca, Can, and Yildirim's study (2013) on 1080 classroom teachers also reflected this finding. Teachers in that study thought that due to heavy curriculum load, they could not allocate adequate time to use technologies in lessons. Not having access to online materials is another challenge. There are certain sites banned by the Ministry of Education. The accessible e-content is not found to be compatible with the national curriculum by the teachers.

Students' Readiness sub-category can be analyzed as their technological readiness, internal motivation, and their parents' readiness to technology. In terms of their technological readiness, teachers complained that some students harm the technology in the classroom, some students do not have technological competence, and some do not have technology at home to continue the work they start in the classroom. Some students' reluctance and difficulty of getting their attention are categorized as their internal motivation to use technology. There are teachers who stated that parents do not have technology or do not know how to use technology (such as computers and internet) and this hinders them from being involved in online groups, share interactively with the teachers or other parents. Some teachers also complained that there are parents who have a negative attitude towards 
technology use in the classroom because they presume teachers just start the computer and do not teach anymore.

The last sub-category under this theme is Teacher Competencies that could be expressed as their Technological, Pedagogical, and Content Knowledge (TPACK). In terms of challenges related with Technological Pedagogical Knowledge, teachers do not know how to involve students to the activities and they do not know how to manage classroom when using technology. Some teachers complained that students wanted to use the computer all at the same time and with equal times for each student and some complained that they feel themselves they need to stand still and not move when doing the lesson using the computer. Controlling students' technology use is another problem. As expressed by one of the teachers: "So far, we have used the technology they gave us but with the use of the tablets, attention deficit problems have started because students can access to other sites on their tablets. I would like to have a mechanism to control students' tablets on our own tablets".

Similar findings to these were highlighted again in Grundmeyer's study (2013). Grundmeyer also concluded that technology can become a distraction to the educational environment if not used as an effective learning tool and the insufficient training for staff in the 1:1 study did result in student distractions. Minimizing such distractions requires that teachers have the skills and training to fully leverage the new technology for instructional purposes.

Teachers also have incompetence in their Technology Knowledge because they think "it takes time to use technology effectively". Many of them expressed that they are not competent in operation systems and using smart/interactive boards, do not know how to prepare documents on computer, and lack the ability to fix hardware problems on their own. Expressing that not having enough time to prepare course content and not knowing about educational sites show the teachers' problems with their Technological Content Knowledge.

Teachers were also asked to list skills they wanted to develop related with the use of technology in their classrooms. The majority of the teachers $(n=290)$ wanted to improve their skills of using interactive white boards. 58 of them expressed their interest in being able to use new technologies skillfully, including the use of the tablets and 48 of them wanted to improve their hardware and maintenance skills. 196 teachers wanted to develop their software skills (designing a web-page, office programs, preparing animations, learning about new software programs etc.). These hardware and software skills are related with the Technological Knowledge of the teachers. This finding confirms the third sub-category of Instructional issues. In addition to Technological Knowledge, teachers wanted to improve their Technological Pedagogical Knowledge: 94 teachers wanted to improve their teaching skills of instructional technologies and the pedagogical skills related with these (classroom management, choosing the right technology for a specific lesson objective etc.) and 36 teachers wanted to be able to prepare their own e-content and e-materials. However, 108 teachers mentioned that they did not want to develop any skills related with the use of technology.

Teachers' data related with the in-service training that they would like to attend or any suggestions of topics for training, also unfolds their need for mostly Technological Pedagogical Knowledge improvement and they suggested the following content for any in-service training they would like to participate: designing content via technology, time management, and distance learning. They all focused that such training should be hands-on and interactive and not trainer-centered or lecture-type. They also wanted such training to be offered regularly throughout the school year. 
The study on the FATiH project by Pamuk et al. (2013) on 181 teachers and 918 students from 11 pilot schools in 4 provinces supports these findings. The main problems of using technology in that study were found to be as not being able to use the classroom management software, insufficient e-content and digital books, technical obstacles, and the lack of in-service training and inadequate technical support. Similarly, these authors suggested that teachers are trained and supported by using TPACK model.

The Akcaoglu et al. (2014) study on the FATiH project also concluded that "without explicit attention to system-wide, interconnected issues such as preparing administrators, changing curriculum, addressing local contexts, trying new teaching methods, and giving teachers access to sustained opportunities for professional growth" (p.11), technology-related implementation efforts for innovation will not succeed satisfactorily.

\section{Conclusion}

This study reports the needs analysis of a technology planning development for the provincewide implementation of the FATIH project. The results of the needs analysis for teachers show that teachers need the managerial, financial, and technical support from their principals. While a school management indifferent to problems of teachers regarding technology use is very demotivating for the teachers, a management proving any kind of support to teachers, students and parents on technology use will definitely be encouraging for a successful integration of technology to the school culture. In that sense, when we think of a school principal who integrates technology into any kind of administrative, instructional and developmental processes in the school, we can say that this principal acts as a catalyst for school wide technology integration. For example, as an instructional leader, school principal's using Google docs to follow and give feedback on lesson plans; handling the robot website of the school with daily updates; or using social media to fulfill his community leadership role will definitely contribute a lot to create a culture of technology integration by being a model for both teachers, students, parents and the other staff. The technology integration plan models therefore should include leadership strategies for a visionary leadership as the key change management.

Technology initiatives need to have infrastructure to sustain them. Financial support should definitely include investment in the infrastructure of the schools including hardware, software, Internet, and maintenance. Otherwise, these factors become major obstacles in integrating technology to instruction. Therefore, the budget allocation should be reconsidered leaving room for technical support.

The needs analysis also reveals the need for the development of teachers' competencies in TPACK. Technology initiatives like the FATIH Project must include effective training for teachers prior to and during the adoption mostly focusing on improving Technological, Pedagogical, and Content Knowledge of teachers. In countries such as Turkey where education system is centralized, teachers are dependent on the national curriculum. Even with the existence of such a national curriculum, teachers need to improve their autonomy and this could only be done if they are competent in their Technological Pedagogical and Content Knowledge.

To empower their autonomy, we suggest that the technology integration plan model should involve creating opportunities for collaboration among teachers such as the development of 
joint units, networks for learning and sharing of good practices, peer coaching and mentoring systems could be encouraged. It should always be remembered that the failure of so many reforms on teaching and learning in the world are a result of lack of internalization of the new systems by the school administration and lack of professional development opportunities for teachers (Fullan \& Hargreaves, 1996).

The needs analysis reported here provides a basics for the technology integration plan model to be selected for the province of Edirne. As the major issues of this needs analysis are categorized as Executive, Infrastructural, and Instructional issues, we suggest the use of Technological Adoption Model (Allan, Yuen, and Wong, 2003), since this model is focusing on managing the adoption of technological infrastructure, organizational structure and teachers' technical skills.

This needs analysis highlights mostly the need for empowering teachers' TPACK competencies; that is, developing their basic technological knowledge to integrate technology to the curriculum and their pedagogical competencies for technology use in learning environments. The components of Technological Adoption Model match the basic issues identified in this study. In developing this model, the emphasis will be on creating a top-down management as the leadership strategy in order to ensure all teachers reach a minimum level of ICT competence and sharing of teacher-produced course materials as one key implementation strategy to deal with the key issues identified in this study.

\section{References}

Afshari, M., Bakar, A., Luan, W. S., Samah, B. A., \& Fooi, F. S. (2009). Factors affecting teachers' use of information. International Journal of Instruction, 2(1), 77-104.

Akcaoglu, M., Gumus, S., Bellibas, M. S., \& Boyer, D. M. (2014). Policy, practice, and reality: Exploring nation-wide technology implementation in Turkish schools. Technology, Pedagogy, and Education. Retrieved on 3 July 2015 from http://www.tandfonline.com/ doi/pdf/10.1080/1475939X.2014.899264. DOI: 10.1080/1475939X.2014.899264.

Akgun, E., Yilmaz, E. O., \& Seferoglu, S. (2011). Vizyon 2013 strateji belgesi ve Firsatlari Artirma ve Teknolojiyi Iyileştirme Hareketi (FATiH) projesi: Karsilastirmali bir inceleme. Akademik Bilişim, 2(4), 1-9

Akinci, A., Kurtoglu, M., \& Seferoglu, S. (2014). Bir teknoloji politikasi olarak FATiH projesinin basarili olmasi için yapilmasi gerekenler: Bir durum analizi calismasi. Retrieved on 10 April 2014 from http://ab.org.tr/ab12/bildiri/160.pdf.

Akkoyunlu, B. (1995). Bilgi teknolojilerinin okullarda kullanimi ve ögretmenlerin rolü. Hacettepe University The Journal of Education, 11, 105-109.

Albirini, A. (2006). Teachers' attitudes toward information and communication technologies: The case of Syrian EFL teachers. Computers \& Education, 47(4), 373-398.

Allan, H. K., Yuen, N. L. \& Wong, K. C. (2003). ICT implementation and school leadership: Case studies of ICT integration in teaching and learning. Journal of Educational Administration, 41(2), 158-170

Baylor, A. L. \& Ritchie, D. (2002). What factors facilitate teacher skill, teacher morale, and perceived student learning in technology-using classrooms? Computers \& Education, 39(4), 395-414. 
Brickner, D. L. (1995). The effects of first and second order barriers to change on the degree and nature of computer usage of mathematics teachers: A case study. (UMI No. 9540219).

Cakir, R. \& Yildirim, S. (2009). What do computer teachers think about the factors affecting technology integration in schools?. Ilkögretim Online, 8(3), 952-964.

Ciftci, S., Taskaya, S. M., \& Alemdar, M. (2013). The opinions of classroom teachers about Fatih project. Elementary Education Online, 12(1), 227-240.

Ertmer, P. A. \& Ottenbreit-leftwich, A. T. (2010). Teacher technology change: how knowledge, confidence, beliefs, and culture intersect. Journal of Research and Technology in Education, 42(3), 255-284.

Fullan, M. (1992). Successful school improvement: The implementation perspective and beyond. London: Open University Press.

Fullan, M. ve Hargreaves, A. (1996). What's worth fighting for in your school? New York: Teachers College Press.

Genc, M. \& Genc, T. (2013). Ögretmenlerin mesleki gelişmeleri takip etme durumlari: Fatih projesi örnegi. Ahi Evran Universitesi Kirsehir Egitim Fakultesi Dergisi, 14(2), 61-78.

Grundmeyer, T. (2013). Adopting technology: Using student qualitative data and Gartner's Hype Cycle. Journal of Education and Training Studies, 2(1), 207-216.

Gulbahar, Y. (2007). Technology planning: A roadmap to successful technology integration in schools. Computers \& Education, 49, 943-956.

Hew, K. F. \& Brush, T. (2007). Integrating technology into K-12 teaching and learning: Current knowledge gaps and recommendations for future research. Educational Technology Research \& Development, 55, 223-252.

Miles, M. B. and A. M. Huberman. (1994). An expanded sourcebook: Qualitative data analysis (2nd Ed.). Newbury Park, CA: Sage.

ISTE (International Society for Technology in Education). (2009). National educational technology standards for administrators. Retrieved on 10 April 2014 from http://iste.org/standards/nets-for-administrators/nets-for-administratorsstandards.aspx.

Karaca, F., Can, G. \& Yildirim, S. (2013). Technology utilization in elementary schools in Turkey's capital: A case study. Educational Studies, 39(5), 552-567. DOI: 10.1080/03055698.2013.807726

Kaufman, R. \& English, F. (1979). Needs assessment: Concept and application. Englewood Cliffs, NJ: Educational Technology Publications.

Kayaduman, H., Sirakaya, M. \& Seferoğlu, S. S. (2011). Investigation of "Increasing Opportunities and Improvement of Technology" project in terms of teacher competencies. XIII. Akademik Bilişim Konferansi Bildirileri. 2-4 Subat 2011, Inonu Universitesi, Malatya.

Koh, J. H. L. \& Divaharan, S. (2013). Towards a TPACK -fostering ICT instructional process for teachers: Lessons from the implementation of interactive whiteboard instruction. Australasian Journal of Educational Technology, 29(2), 233-247. 
Kurt, A. A., Kuzu, A., Dursun, O. O., Gullupınar, F., \& Gultekin, M. (2013). FATiH projesinin pilot uygulama sürecinin degerlendirilmesi: Ogretmen gorusleri. Journal of Instructional Technologies and Teaching, 2(1), 1-23.

Lai, K.W., Pratt, K. \& Trewern, A. (2001). Learning with technology: Evaluation of the Otago secondary schools technology project. The Community Trust of Otago, Dunedin.

Marshall, E. \& Rossman, G. B. (1989). Designing qualitative research. Newbury Park, CA: Sage.

MEB. (2012). Milli Egitim Bakanligi FATIH projesi. Retrieved on 10 April 2014 from http://fatihprojesi.meb.gov.tr.

Mishra, P. \& Koehler, M. J. (2006). Technological pedagogical content knowledge: A framework for teacher knowledge. Teachers College Record, 108(6), 1017-1054.

Mosenson, A. B. \& Johnson, J. M. (2008). Instructional strategies and resources: Exploring the use of technology. Journal of Family Consumer Sciences Education, 26, 17-35.

Mundy, M. \& Kupczynski, L. (2013). A qualitative study of technology integration into culture and sustainability in schools. Vol. 2013, Article ID 967610. Retrieved on 10 April 2014 from http://dx.doi.org/10.1155/2013/967610

NOAA Manual. (2009). Designing education projects: A comprehensive approach to needs assessment, project planning and implementation, and evaluation (2nd ed.). NOAA: Washington DC.

Pamuk, S., Çakir, R., Ergun, M., Yilmaz, H. B., \& Ayas, C. (2013). The use of tablet PC and interactive board from the perspectives of teachers and students: Evaluation of FATIH Project. Educational Sciences: Theory \& Practice, 13(3), 1815-1822. DOI: 10.12738/estp.2013.3.1734

Pelgrum, W. J. (2001). Obstacles to the integration of ICT in education: Results from a worldwide educational assessment. Computers \& Education, 37(2), 163-178.

Moeller, B. \& Reitzes, T. (2011). Integrating technology with student-centered learning: A report to the Nellie Mae Education Foundation. Quincy, MA: Nellie Mae Education Foundation.

Roblyer, M. D. (2006). Integrating educational technology into teaching. New York: Pearson Education.

Saban, A. (2007). Seçmeci okul teknoloji planlama modeli ve Ozel Konya Esentepe Ilkogretim Okulu teknoloji profili. Sosyal Bilimler Enstitusu Dergisi, 22(1), 23-43.

Strauss, A. M. \& Corbin, J. (1998). Basics of qualitative research: Techniques and procedures for developing grounded theory ( $3^{\text {rd }}$ ed.). Newbury Park, CA: Sage.

Sugar, W. \& Holloman, H. (2009). Technology leaders wanted: Acknowledging the leadership role of a technology coordinator. TechTrends, 53(6), 66-74.

Thompson, A. D., Schmidt, D. A., \& Davis, N. E. (2003). Technology collaboratives for simultaneous renewal in teacher education. Educational Technology Research and Development, 51(1), 124-128.

Tondeur, J., Braak, J. V., Sang, Guoyuan, Voogt, J., Fisser, P., and Ottenbreit-Leftwich, A. (2012). Preparing pre-service teachers to integrate technology in education: A synthesis of qualitative evidence. Computers \& Education, 59, 134-144. 
Uzoglu, M. \& Bozdogan, A. E. (2012). An examination of preservice science teachers' views related to use of tablet PCs in science and technology course in terms of different variables. Mevlana International Journal of Education, 2(1), 1-14.

Correspondence: Sirin Karadeniz, Associate Professor, Department of Computer Education and Instructional Technologies, Faculty of Educational Sciences, Bahcesehir University, Istanbul, Turkey 